\title{
Sound insulation of lightweight partition walls with regard to structural sound transmission
}

\author{
Olga Lelyuga ${ }^{1, *}$, and Sergey Ovsyannikov ${ }^{1}$ \\ ${ }^{1}$ Tomsk State University of Architecture and Building, 634003 Tomsk, Russia
}

\begin{abstract}
The known methods of acoustical calculation in buildings disregard the phenomenon of structural sound transmission, whereas its effect can reach from 2 to $12 \mathrm{~dB}$. The purpose of this paper is to develop the calculation method for sound transmission and vibrations in connected vibroacoustic systems. Theoretical research methods were used based on the theory of statistical energy analysis (SEA) and the theory of selfconsistent sound fields with regard to dual nature of sound formation resonance and inertia. Based on M. Sedov's method of sound fields consistency, a calculation method for sound insulation was developed with integration in SEA methodology. Use of the developed method allows predicting sound transmission through a double-panel partition with the account of adjacent structures.
\end{abstract}

\section{Introduction}

One of the topical tasks of civil and architectural engineering is design of partitions with relatively small mass. This allows decreasing both load on load-bearing structures and material consumption. The main requirement to partitions consists in standard sound insulation performance. The use of multilayer structures provides high sound insulation with considerable reduction of area weight [1,2]. For effective sound insulation in partitions structural parameters of these partitions shall be accounted along with conditions of sound vibration transmission in adjacent structures. Experimental studies show [3] that structural sound transmission effect on sound insulation of partitions can reach from 2 to 12 $\mathrm{dB}$.

Acoustic and vibration sound sources cause sound vibration in the building frame in the form of elastic waves: longitudinal, transverse or bending [4]. A combination of factors cause disturbance of acoustic comfort in rooms both adjacent to and remote from the source of sound or vibration. Mechanical vibrations of walls, floorings or pipelines occurring in one room are transmitted to a considerable distance with little vibration loss and are emanated in the air as audible sound. Lightweight structures with big surface area emanate sounds particularly well. Vibrations can be caused by direct action (footsteps, door slam, vibrations of pipelines and technical appliances) or can be the consequence of airborne sound action.

*Corresponding author: olga.startseva27@gmail.com 
The methods for buildings and structures calculation known to date [5-10] disregard the phenomenon of structural sound transmission. In this relation, theoretical and experimental research is required to investigate transmission of sound and vibrations in connected vibroacoustic systems of building models.

Sound is transmitted through joints of double panels, for instance, lightweight partitions adjoined to load-bearing walls and floorings, joints between interior and exterior structures, in case the latter consist of two panels, etc. (Fig. 1) Joints of double-panel structures may have elastic plugs or gaskets under flooring plates. Thickness of adjoined panels may vary [4].

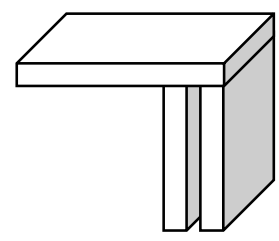

a)
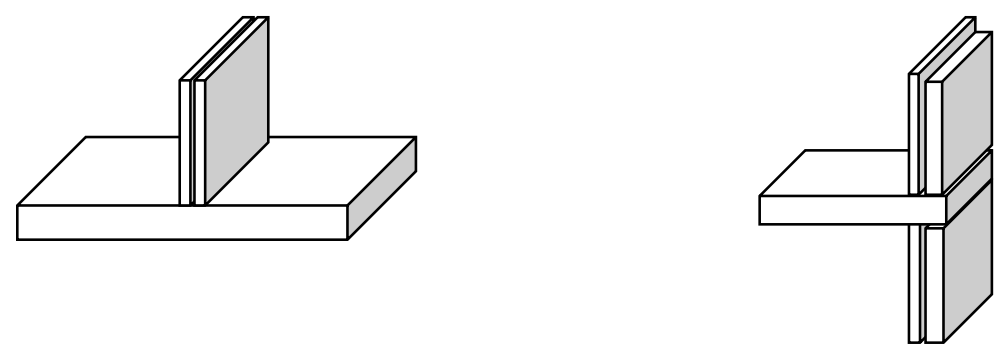

b)
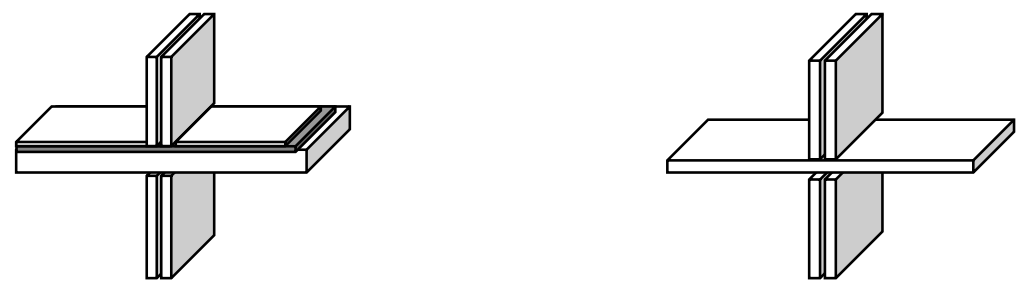

c)

Fig. 1. Joints of double-panel partitions: a) angle joint; b) T-shaped joint; c) X-shaped joint.

Stiffness of joints with elastic plugs is characterized by the elastic modulus of the plug material and its geometrical parameters. Stiff joints can be obtained by equaling the elastic modulus of the plug material to that of the main structures material.

The problem of sound transmission through the joint of a two-panel partition can be solved using the SEA theory by writing a system of equations which describes energy relation of separate structural elements [4]. Energy balance equations account resonance properties and dissipative characteristics of such elements which are considered as subsystems in the common system of the studied building fragment. The SEA method in general statement used for defining energy coupling coefficients only accounts resonant sound transmission while disregarding the non-resonant one. Such omission can lead to considerable error in forecasting sound transmission. 
The most complete analysis of sound transmission through a two-panel partition joint can be performed using the M. Sedov's theory of sound fields consistency [10].

The method of two-panel partitions calculation [10] developed by the research group of M. Sedov is based on the theory of sound fields consistency in the partition plane and the plate wave field formed by natural waves. The method accounts the dual nature of sound formation - resonance and inertia. The main paths of sound transmission through two-panel structures herein include not only those through plates and air space, but also paths of sound vibrations propagated along the adjoined structures. This method enables to account all forms of sound transmission while performing SEA.

The paper presents the calculation method for sound insulation based on M. Sedov's method of sound fields consistency, with integration in SEA methodology.

The alternative approach to calculation of resonant sound transmission is suggested by F. G. Leppington [14]. However, this approach has a number of limitations like the need of ideal boundary conditions which cannot be easily adopted in the structure of SEA used in this paper.

\section{Research method}

\subsection{SEA Model}

The first stage of using SEA includes building a physical model in which the whole studied system is divided into elements and subsystems. To represent energy coupling of subsystems in the SEA model, let us consider the system of three panels (structural subsystems) and two air volumes of a room (acoustic subsystems).

The scheme of energy coupling of room partitions is presented in Figure 2.

The subscript indices of $I, I I$ are used to mark the room numbers, and the subscript indices of 1, 2 and 3 denote the panels which exchange bending wave energy. The sequence of the indices shows the direction of energy flow. The superscript characters indicate the type of wave field in the model elements, $A$ - stands for acoustic field in the room, and $b-$ for bending wave field in a panel. $W_{1}, W_{2}, W_{2}, W_{I}$ и $W_{I I}$ - energies in subsystems, $P_{1}, P_{2}$ and $P_{3}$ - external power supplied into the subsystems, $P_{1, \text { diss }}, P_{2, \text { diss }}$, and $P_{3, \text { diss }}-$ dissipated power in the subsystems, $P_{12}, P_{21}, P_{23}, P_{32}$ and $P_{13}, P_{31}$ - power of energy exchange between subsystems.

Powers that are lost in subsystems can be expressed in the following way:

$$
\begin{aligned}
& P_{1, \text { diss }}^{b}=\omega \cdot \eta_{1}^{b} \cdot W_{1}^{b} \\
& P_{2, \text { diss }}^{b}=\omega \cdot \eta_{2}^{b} \cdot W_{2}^{b} \\
& P_{3, \text { diss }}^{b}=\omega \cdot \eta_{3}^{b} \cdot W_{3}^{b},
\end{aligned}
$$

where $\eta_{1}^{b}, \eta_{2}^{b}, \eta_{3}^{b}$ - internal loss factors in subsystems in the process of bending waves propagation; $\omega=2 \pi f$ - angular frequency taken as a geometric mean frequency of onethird octave and octave band. 


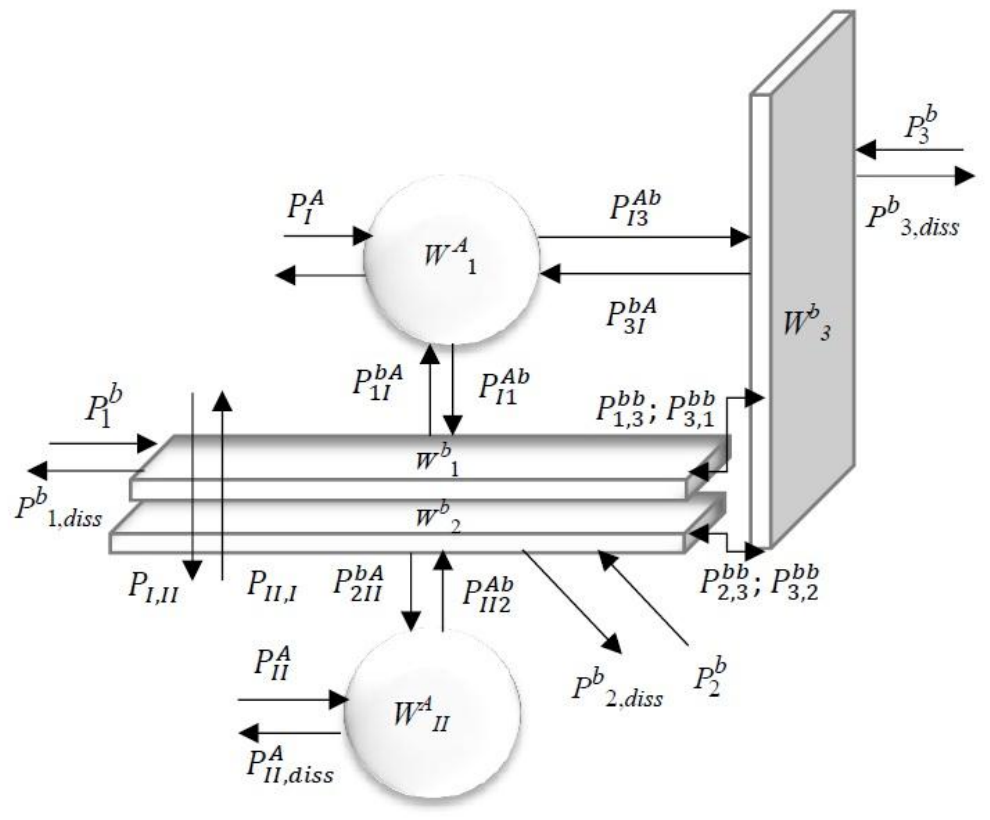

Fig. 2. Scheme of energy exchange between acoustic and structural subsystems in the process of bending wave propagation in panels.

Now, let us write an energy balance equation for each panel and for two acoustic subsystems:

$$
P_{I}^{A}=\omega \cdot \eta_{I, I}^{A} \cdot W_{I}^{A}-\omega\left(\eta_{1 I}^{b A} \cdot W_{1}^{b}+\eta_{3 I}^{b A} \cdot W_{3}^{b}\right),
$$

where $\eta_{I, I}^{A}=\eta_{I}^{A}+\eta_{I 1}^{A b}+\eta_{I 3}^{A b}+\eta_{I, I I}^{A A}$

$$
P_{I I}^{A}=\omega \cdot \eta_{I I, I I}^{A} \cdot W_{I I}^{A}-\omega \cdot \eta_{2 I I}^{b A} \cdot W_{2}^{b},
$$

where $\eta_{I I, I I}^{A}=\eta_{I I}^{A}+\eta_{I I 2}^{A b}+\eta_{I I, I}^{A A}$

$$
P_{1}^{b}=\omega \cdot \eta_{1,1}^{b} \cdot W_{1}^{b}-\omega \cdot\left(\eta_{I 1}^{A b} \cdot W_{I}^{A}+\eta_{3 I}^{b b} \cdot W_{3}^{b}\right),
$$

where $\eta_{1,1}^{b}=\eta_{1}^{b}+\eta_{1 I}^{b A}+\eta_{13}^{b b}$

$$
P_{2}^{b}=\omega \cdot \eta_{2,2}^{b} \cdot W_{2}^{b}-\omega \cdot\left(\eta_{I I 2}^{A b} \cdot W_{I I}^{A}+\eta_{32}^{b b} \cdot W_{3}^{b}\right),
$$

where $\eta_{2,2}^{b}=\eta_{2}^{b}+\eta_{2 I I}^{b A}+\eta_{23}^{b b}$

$$
P_{3}^{b}=\omega \cdot \eta_{3,3}^{b} \cdot W_{3}^{b}-\omega \cdot\left(\eta_{I 3}^{A b} \cdot W_{I}^{A}+\eta_{13}^{b b} \cdot W_{1}^{b}+\eta_{23}^{b b} \cdot W_{2}^{b}\right),
$$

where $\eta_{33}^{b}=\eta_{3}^{b}+\eta_{3 I}^{b A}+\eta_{31}^{b}+\eta_{32}^{b b}$

In a number of cases, including full-scale measurement of propagation of noise and sound vibration in a building, the power of source can be evaluated using the measured or calculated sound pressure level Lpk in a room where the sound source is located [11]:

$$
P_{k}^{A}=\frac{A_{k}}{4 \cdot 10^{12}} \cdot 10^{0.1 \cdot L_{p k}}
$$


where $L_{p k}$ - sound pressure level measured at a number of different points in a room and averaged; $A_{k}$ - equivalent absorption in a room ( $k$ - acoustic subsystem).

$$
A_{k}=0,163 \frac{\mathrm{V}}{T},
$$

where $T$ - reverberation time, $\mathrm{s} ; V$ - room volume, $\mathrm{m}^{3}$.

Other powers are equal to 0 , for no sound or vibration source affects the panel and the second room.

The solution consists in composing linear power equations to calculate the unknown energies $W_{1}^{b}, W_{2}^{b}, W_{3}^{b}, W_{I}^{A}, W_{I I}^{A}$ in each subsystem. Sound level is found for a room to define its sound insulation:

$$
L_{k}=10 \lg \frac{W_{k}^{A} \cdot c_{o}}{P_{o} \cdot V_{k}},
$$

where $c_{0}=344 \mathrm{~m} / \mathrm{s}$ - speed of airborne sound; $P_{0}=10^{-12} \mathrm{~W}$ - power threshold value.

\subsection{Energy coupling factors}

\subsubsection{Energy coupling factors for panel and air volume of a room}

Energy coupling factors for a panel and air volume of a room can be found using the Cramer's formula [12]

$$
\eta_{i k}^{b A}=\frac{p \cdot c_{o} \cdot \sigma_{i}}{2 \pi \cdot f \cdot p_{i} \cdot h_{i}}
$$

where $\rho \cdot c_{0}=410 \mathrm{H} \mathrm{s} / \mathrm{m}^{3}$ - acoustic impedance of air ( $\rho$ - air density, $c_{0}-$ speed of airborne sound); $\rho_{i}$ and $h_{i}-$ volumetric weight and thickness of $i$ structure; $\sigma_{i}-$ sound radiation coefficient.

$$
\begin{aligned}
& \sigma=\frac{U \cdot \lambda_{c}}{\pi^{2} \cdot s} \cdot \sqrt{\frac{f}{f_{c}}}, \text { with } f<<f_{c} \\
& \sigma=0.45 \cdot \sqrt{\frac{U}{\lambda_{c}}}, \text { with } f=f_{c} \\
& \sigma=1, \text { with } f<<f_{c},
\end{aligned}
$$

where $S$ - panel area; $U$ - panel perimeter; $\lambda_{c}$ - wave length at cutoff frequency; $f_{c}-$ cutoff frequency which can be found in the following formula:

$$
f_{c}=\frac{\sqrt{3} \cdot c_{o}^{2}}{\pi h \cdot c_{l}}
$$

where $c_{l}$ - longitudinal wave velocity in a panel.

The energy coupling factor for air volume and a panel $\eta_{k i}^{A b}$ can be found using inverse factor $\eta_{i k}^{b A}$ defined through the formula (12) as follows:

$$
\eta_{k i}^{A b} \cdot n_{k}^{A}=\eta_{i k}^{b A} \cdot n_{i}^{b}
$$

where $n_{k}^{A}$ - density of natural vibrations (modal density) in a room; $k ; n_{i}^{b}-$ density of natural bending vibrations in a panel. 


\subsubsection{Internal sound energy loss in a room}

In the SAE model, internal sound energy loss in a room is described by internal loss factor $\eta_{k}^{A}$ :

$$
\eta_{k}^{A}=13.5 \cdot \frac{A_{k}}{f \cdot V_{k}}
$$

where $f$-geometric mean frequency of a band; $A_{k}$ - equivalent sound absorption in a room; $V$ - room volume, $\mathrm{m}^{3}$.

\section{Results}

\section{Coefficients of energy coupling between panels}

Resonant transmission is considered by the SAE model, whereas non-resonant room-toroom transmission through a wall is considered by the method of mutual coupling of sound fields.

It is suggested to determine coefficients of energy coupling between rooms using inertial transmission coefficient in a formula of R.J.M. Craik [13] which can be presented in as follows:

$$
\eta_{I, I I}=\frac{c_{0} \cdot S \cdot \tau_{i j}}{8 \cdot \pi \cdot f \cdot V}
$$

where $c_{0}$ - wave velocity in the air, $S$ - surface area, $\tau_{i j}$ - inertial transmission coefficient for $i$ and $j$ structures, $V$ - room volume, $\mathrm{m}^{3}$.

The inertial sound transmission coefficient is calculated using M. Sedov's formula [10]:

$$
\tau=\tau_{n u}+\tau_{1 u} \cdot \tau_{2 u},
$$

where $n$ indices denote sound transmission through plates with elastic coupling. At the same time,

$$
\tau_{n u}=1 /\left\{\left[\frac{\pi^{2}}{p_{o}^{2} c_{o}^{2}} \cdot \frac{m^{\prime 2} f^{2}}{F_{1 u . c p}^{2}}\left(\frac{f^{2}}{f_{o}^{2}}-1\right)^{2}\right]+1\right\}
$$

Here, $m^{\prime}=m_{1}+m_{2}$, where $m_{1} m_{2}$ - surface of the first and the second structures, $F_{1 u}$ - response function of the first plate affected by sound [10], $f_{0}$ - resonant frequency of the system "mass-elasticity-mass":

$$
f_{o}=60 \sqrt{\frac{m_{1}+m_{2}}{L m_{1} m_{2}}}
$$

$L$ - distance between the plates, $\mathrm{m}$.

Inertial sound successive transmission through the first and the second plates divided by air space is determined using the following coefficients:

$$
\begin{aligned}
\tau_{1 u} & =1 /\left(\frac{\pi^{2}}{p_{o}^{2} c_{o}^{2}} \cdot \frac{m_{1}^{2} f^{2} \cos ^{2} \theta_{1}}{F_{1 u . c p}^{2}}+1\right) \\
\tau_{2 u} & =1 /\left(\frac{\pi^{2}}{p_{o}^{2} c_{o}^{2}} \cdot \frac{m_{2}^{2} f^{2} \cos ^{2} \theta_{2}}{F_{2 u . c p}^{2}}+1\right),
\end{aligned}
$$


where $\theta_{2}$ - angle of incidence between the second plate and the sound waves forming natural vibrations in the air space along the planes of the plates. In the majority of actually used structural solutions for two-panel partitions $\cos \theta_{2}=L / \sqrt{a^{2}+L^{2}}[10]$.

\section{Conclusion}

This paper presents a physical model of a two-panel partition with an adjoined panel. Systems of equations describing energy coupling between separate structural elements are produced.

The suggested calculation method accounts both resonant and non-resonant sound transmission forms while defining energy coupling coefficients. The obtained outcomes are based on complete analysis of sound transmission through the joint of a two-panel partition.

Further extension of the performed research require experimental study of the developed calculation method. The experiment shall solve both direct and inverse problems of SEA with calculation of energy coupling coefficients between panels and between air volumes.

\section{References}

1. A.A. Kochkin, I.L. Shubin, Zvukoizoljacija legkih ograzhdajushhih konstrukcij zdanij iz jelementov s vibrodempfirujushhimi slojami [Sound insulation of lightweight envelope structures using elements with vibration damping layers], Doctoral thesis, Vologda State University, 2013 (in Russian)

2. V.N. Bobylev, V.A. Tishkov, P.A. Grebnev, D.V. Monich, Vestnik Volzhskogo regional'nogo otdeleniya RAASN [Proceedings of Volga Regional Department of Russian Academy of Architecture and Construction Sciences], 18, 96-99 (2015) (in Russian)

3. B.G. Kreitan, Zashhita ot vnutrennih shumov v zhilyh domah [Protection against internal noises in residential houses], (Strojizdat, Moscow, 1990) (in Russian)

4. S.N. Ovsyannikov, Rasprostranenie zvukovoj vibracii v grazhdanskih zdanijah [Propagation of sound vibration in civil buildings], (TSUAB Publishing house, Tomsk, 2000) (in Russian)

5. G.L. Osipov, Shumy i zvukoizoljacija [Noises and sound insulation] (Strojizdat, Moscow, 1967) (in Russian)

6. V.I. Zaborov, E.M. Lalaev, V.N. Nikolski, Zvukoizoljacija v zhilyh i obshhestvennyh $z$ danijah [Sound insulation in residential and public houses] (Strojizdat, Moscow, 1979) (in Russian)

7. V.I. Zaborov, M.I. Mogilevskiy, V.N. Myakshin, E.P. Samoilyuk, Spravochnik po zashhite ot shuma $i$ vibracii zhilyh $i$ obshhestvennyh zdanij [Handbook on residential and public buildings protection against noise and vibration] (Budivjel'nik, Kiev, 1989) (in Russian)

8. I.I. Bogolepov, Promyshlennaja zvukoizoljacija [Industrial sound insulation], (Sudostroenie, Leningrad, 1986) (in Russian)

9. V. Blazi, Spravochnik proektirovshhika [Handbook of a civil engineer. Building physics], (Tehnosfera, Moscow, 2005)

10. M.S. Sedov, News of Higher Educational Institutions. Construction and Architecture, 2, 37-42 (1990) (in Russian)

11. V. Anert, V. Reihard, Osnovy tehniki zvukousilenija [Fundamentals of sound reinforcement equipment], (Radio i svjaz', Moscow, 1984) (in Russian) 
12. L. Cremer, M. Heckl, E. Ungar, Structure-borne sound, (Springer Verlag, Berlin, 1973)

13. R.J.M. Craik, R.S. Smith, Applied Acoustics, 61, 223-245 (1999)

14. F.G. Leppington, K.H. Heron, E.G. Broadbent, S.M. Mead, Proceedings of the Royal Society of London, 412, 309-337 (1987) 